\title{
Core needle biopsy promotes lung metastasis of breast cancer: An experimental study
}

\author{
YONGQIANG FU ${ }^{1}$, FANGMING GUO ${ }^{1}$, HAOHAO CHEN ${ }^{1}$, YIPING LIN ${ }^{1}$, \\ XIAOYAN FU ${ }^{1}$, HUI ZHANG ${ }^{2}$ and MINGXING DING ${ }^{1}$ \\ ${ }^{1}$ Department of Medical Sciences, Jinhua Polytechnic, Jinhua, Zhejiang 321007; \\ ${ }^{2}$ Department of Laboratory Animals Center, Jinhua Institute for Food and Drug Control, Jinhua, Zhejiang 321000, P.R. China
}

Received June 25, 2018; Accepted November 30, 2018

DOI: $10.3892 / \mathrm{mco} .2018 .1784$

\begin{abstract}
Core needle biopsy (CNB) may be used to diagnose early-stage breast cancer, but it may increase the risk of distant metastasis of tumor cells. The aim of the present study was to explore the effect of CNB on the distant metastasis of breast cancer. A total of $30 \mathrm{BALB} / \mathrm{c}$ mice were divided into two groups, namely biopsy and non-biopsy groups. The biopsy-related lung metastasis model (biopsy group) was established by the inoculation in the mammary fat pad of the mouse breast cancer cell line 4T1 combined with CNB. Flow cytometry, quantitative polymerase chain reaction analysis, morphological analysis, as well as other techniques, were used to evaluate the biological behavior of the tumors in the mouse model. A stable and reliable lung metastasis model of breast cancer was successfully established. The number of metastatic lung nodules in the biopsy group was significantly higher compared with that in the non-biopsy group $(\mathrm{P}<0.05)$. Compared with the non-biopsy group, the mRNA expression of transforming growth factor (TGF)- $\beta 1$, SOX4 and Ezh 2 in the biopsy group was significantly upregulated $(\mathrm{P}<0.05)$ and the number of natural killer (NK) cells detected by flow cytometry was increased, but the difference was not statistically significant $(\mathrm{P}>0.05)$. Therefore, $\mathrm{CNB}$ was found to promote the lung metastasis of breast cancer, and the underlying mechanism may be associated with epithelial-to-mesenchymal transition (EMT) mediated by the TGF- $\beta 1$ signaling pathway.
\end{abstract}

Correspondence to: Dr Mingxing Ding, Department of Medical Sciences, Jinhua Polytechnic, 1188 Wuzhou Road, Jinhua, Zhejiang 321007, P.R. China

E-mail: dingmx@sina.com

Abbreviations: CNB, core needle biopsy; DMEM, Dulbecco's modified Eagle's medium; EMT, epithelial-to-mesenchymal transition; FBS, fetal bovine serum; H\&E, hematoxylin and eosin; qPCR, quantitative polymerase chain reaction; RT, reverse transcription

Key words: breast cancer, lung metastasis, biopsy, epithelial-tomesenchymal transition, mouse

\section{Introduction}

Breast cancer ranks first in incidence and mortality among malignancies in women; cancer invasion and metastasis are the major causes of death. The tumor size and lymph node involvement at diagnosis are recognized as the main indices among the numerous factors affecting the metastatic potential of breast cancer. Hence, screening and early detection are crucial for improving the prognosis and quality of life of the patients $(1,2)$. At present, core needle biopsy (CNB) is the main diagnostic method used, but its impact on clinical outcome and the potential risks remain controversial. Studies have found that CNB can increase the possibility of metastasis of tumor cells to the skin at the needle puncture site in patients with breast cancer, and it may also increase the risk of local recurrence and distant metastasis $(3,4)$.

In clinical practice, it has been found that surgical intervention, including excisional biopsy, is associated with a higher local recurrence rate and lymph node metastasis, and surgical trauma can promote the growth and metastasis of the original tumor. The underlying mechanism may involve a series of interactions between tumor cells and the extracellular matrix. Epithelial-to-mesenchymal transition (EMT) is a biological process involving the transition of epithelial cells to a mesenchymal phenotype through specific procedures during early embryonic development. EMT is important for cancer invasion and metastasis, and is closely associated with poor clinical outcome. After EMT, the primary tumor cells may detach, migrate into the vessels, become circulating tumor cells and colonize distant organs, in which the tumor completes the mesenchymal-to-epithelial transition, and the cells proliferate leading to metastasis formation. E-cadherin is an epithelial cell adhesion molecule, the loss of function of which is an important marker of EMT. It has been found that, in addition to sub-Snail, zinc finger E-box-binding protein, Twist and other transcription factors can initiate the EMT process. Signaling pathways, such as transforming growth factor (TGF)- $\beta$, Wnt, Notch and Hedgehog, and hypoxic conditions, can also participate in the regulation of E-cadherin expression and EMT. Furthermore, the TGF- $\beta$ superfamily can activate a number of complex signaling pathways, such as Smad and non-Smad, facilitating the occurrence and metastasis of breast cancer through EMT mediated by several downstream 
transcription factors (5). Recently, SOX4 of the SRY-related HMG-box (SOX) family of transcription factors has been found to be involved in regulating the TGF- $\beta$-induced EMT of human breast epithelial cancer cells through epigenetic modification of the Enhancer of Zeste homolog 2 (Ezh2) gene, which may be used as a potential biomarker of triple-negative breast cancer in the clinical setting $(6,7)$.

In the present study, the biopsy-related lung metastasis model (biopsy group) was established by inoculation in the mammary fat pad of the mouse breast cancer cell line 4T1 combined with CNB $(8,9)$. The activation of TGF- $\beta$, SOX4 and Ezh2 genes confirmed the promoting effect of EMT on distant metastasis, thereby providing the basis for the correct evaluation of biopsy, effectiveness and safety of surgery, and exploration of the biological mechanism underlying the lung metastasis of breast cancer.

\section{Materials and methods}

Reagents and instruments. The mouse breast cancer cell line 4T1 was provided by Cell Bank, Shanghai Institutes for Biological Sciences, Chinese Academy of Sciences (Shanghai, China). L-glutamine, Dulbecco's modified Eagle's medium (DMEM) and fetal bovine serum (FBS) were all obtained from Gibco; Thermo Fisher Scientific, Inc. (Waltham, MA, USA). High-purity total RNA rapid extraction kit (Generay Biotech Co., Ltd., Shanghai, China; GK3016), reverse transcription kit HiScript-II Q RT SuperMix for quantitative polymerase chain reaction (qPCR) analysis (Vazyme Biotech Co., Piscataway, NJ, USA; R222-01), qPCR reagent ChamQ SYBR Color qPCR Master Mix (Vazyme Biotech Co., Piscataway, NJ, USA; Q411-02), experimental primers (synthesized and purified by Shanghai Sunny Biotech Co., Ltd., Shanghai, China), anti-mouse CD49b-APC antibody (eBio-science, Waltham, MA, USA;17-5971-81), anti-mouse CD3-FITC antibody (eBio-science, Waltham, MA, USA;11-0032-80), a flow cytometer (Accuri C6; BD Biosciences, Franklin Lakes, NJ, USA), the BX43 light microscope (Olympus Corporation, Tokyo, Japan), and a watertight constant-temperature incubator (PYX-DHS500BS-II; Shanghai Yuejin Medical Instruments Co., Ltd., Shanghai, China) were also used.

Animals and feeding. A total of 30 4-6-week-old female specific pathogen-free BALB/c mice, weighing 16-20 g, were provided by the Shanghai Laboratory Animal Center Co., Ltd., Shanghai, China [production certification no. SCXK (Hu) 2012-0002, certification no. 0300203). The animals were provided with sterilized grade 2 ultrapure water, which was in accordance with the national standards of PRC Sanitary Standard for Drinking Water (GB5749-2006) (10). The license number of the laboratory animal room was SYXK (Zhejiang) 2015-0008, and the conditions included a temperature range of $20-25^{\circ} \mathrm{C}$ and the relative humidity range of $40-70 \%$. The feed was provided by Shanghai Laboratory Animal Center Co., Ltd., in accordance with the standardized operation GB14924.3-2010 Nutritional Components of Feeds for Experimental Animals (11). This study was approved by the Animal Ethics Committee of the JinHua Center of Laboratory Animals, Jinhua Institute for Food and Drug Control (Jinhua, China). The animals were housed and the experiments were performed at the JinHua Center of Laboratory Animals, and all experimental procedures were performed in accordance with the animal testing regulations.

Cell culture. The 4T1 cells were cultured in DMEM containing $10 \% \mathrm{FBS}, 100 \mathrm{IU} / \mathrm{ml}$ penicillin and $100 \mathrm{~g} / \mathrm{ml}$ streptomycin in a $5 \% \mathrm{CO}_{2}, 37^{\circ} \mathrm{C}$ incubator.

Establishment of mouse breast carcinoma in situ and lung metastasis model. After BALB/c mice were anesthetized by intraperitoneal injection of $1 \%$ pentobarbital $(60 \mathrm{mg} / \mathrm{kg})$, an incision of $2 \mathrm{~cm}$ was made in the middle of the thorax under aseptic conditions, followed by blunt dissection to the bilateral mammary fat pad for cell inoculation. 4T1 cells in the exponential growth phase were collected and centrifuged at $300 \mathrm{x}$ g for $5 \mathrm{~min}$. The cell concentration was adjusted to $2 \times 10^{5}$ cells $/ \mathrm{ml}$ to prepare a single-cell suspension, which was mixed by blowing with a 1-ml empty needle. Then, $0.05 \mathrm{ml}$ was inoculated into the third bilateral mammary fat pad of the $\mathrm{BALB} / \mathrm{c}$ mice $\left(1 \times 10^{4}\right.$ cells for each side), followed by suturing of the incision after notable skin bulges had appeared at the injection site and the mice were monitored until palpable masses developed. At 3 weeks after inoculation, the tumor diameter was $\sim 6 \mathrm{~mm}$ in most of the BALB/c mice, which were used for subsequent experiments.

Biopsy and tumor resection. The mice were divided into two groups (biopsy and non-biopsy), each consisting of 15 mice. In the biopsy group, the mice were anesthetized by intraperitoneal injection of $1 \%$ pentobarbital $(60 \mathrm{mg} / \mathrm{kg})$ for 3-5 min and then fixed, with the tumor side up, followed by disinfection of the tumor site with iodophor for preparation. CNB of the tumor was performed using a $5-\mathrm{ml}$ syringe with an $18 \mathrm{G}$ needle. The needle was inserted at the center of the tumor and then moved six to eight times in a palmate-radiating pattern, ensuring that the puncture sites were evenly distributed in the tumor. The mice in the non-biopsy group were anesthetized by intraperitoneal injection of $1 \%$ pentobarbital $(60 \mathrm{mg} / \mathrm{kg})$. The tumor was not punctured, but the mice underwent surgical preparation with complete anesthesia and were placed in the same laboratory for the same duration.

The mice in the biopsy and non-biopsy groups underwent tumorectomy 7 days after CNB. The animals were injected intraperitoneally with $1 \%$ pentobarbital sodium $(60 \mathrm{mg} / \mathrm{kg})$. After 3-5 min, they were systemically sterilized with iodophor. Under sterile conditions, a 2- to 3-cm incision was made in the middle of the thorax. The breast tumors were resected, and all tumor tissue was removed to prevent local recurrence. Postoperatively, the incision was sutured and disinfected with iodophor again to prevent infection. Subsequently, at 1 and 2 weeks after resection of the breast cancer, the pulmonary metastasis nodules were also removed under anesthesia for PCR analysis and other tests.

Morphological and histopathological examinations. The resected tumor tissue was cryopreserved in liquid nitrogen for subsequent PCR analysis, as well as immunohistochemical and other histopathological analyses. The growth of the breast tumors was monitored daily from the inoculation of 
Table I. Primer sequences.

\begin{tabular}{lll} 
Gene & \multicolumn{1}{c}{ Forward primer $\left(5^{\prime}-3^{\prime}\right)$} & Reverse primer $\left(3^{\prime}-5^{\prime}\right)$ \\
\hline TGF- $\beta 1$ & AGGGCTACCATGCCAACTTC & CCACGTAGTAGACGATGGGC \\
SOX4 & CGCCCGACATGCACAAC & TGCCCGACTTCACCTTCTTT \\
Ezh2 & CAACCCGAAAGGGCAACA & CCCACATACTTCAGGGCATCA \\
-actin & AGAGGGAAATCGTGCGTGAC & CCAAGAAGGAAGGCTGGAAA
\end{tabular}

TGF- $\beta 1$, transforming growth factor- $\beta 1$; Ezh2, Enhancer of Zeste homolog 2.

A

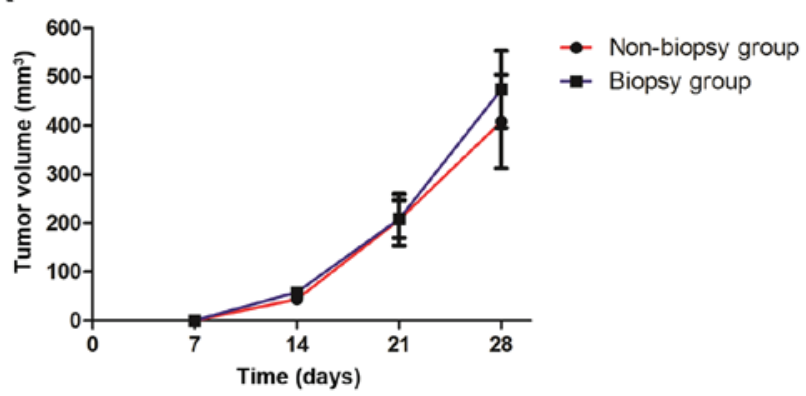

B

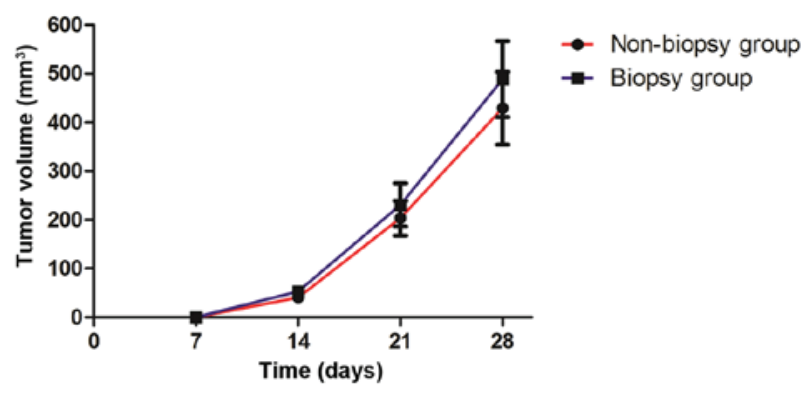

Figure 1. Growth curve of mouse breast tumors (mean \pm standard deviation, $\mathrm{mm}^{3}$ ). The model of breast cancer in situ in BALB/c mice was successfully established 14 days after the inoculation of the breast cancer cell line 4T1. The size of the bilateral tumors was measured weekly from the inoculation of tumor cells to the resection of breast tumors, and the volume of tumors was evaluated. The growth curves of right side tumors (A) and of left side tumors (B) were plotted. At 7 days after the biopsy, the tumor volume in the biopsy group was higher compared with that in the non-biopsy group, but the difference was not statistically significant $(\mathrm{P}>0.05)$.

tumor cells to the resection of breast tumors, and the size of the lumps was measured weekly. The size of the bilateral tumors was evaluated using the equation: Tumor volume $=1 / 2$ (long diameter $\mathrm{x}$ short diameter ${ }^{2}$ ), and growth curves were plotted (12). Starting at 1 week after biopsy, three BALB/c mice were sacrificed every week, until all the mice had been sacrificed.

After 45 days of tumor growth, the mice were euthanized and the lungs were collected to count the number of metastatic pulmonary nodules (macroscopic metastatic nodule count) and measure the diameter of metastatic tumors under an anatomical microscope. The number of metastatic tumor foci on the lung surface was calculated using the equation: I x $1+$ II $x 2+$ III x $3+$ IV $x 4$ (based on the diameter of the pulmonary metastases, it was classified into four grades: Grade I, $<0.5 \mathrm{~mm} ; 0.5 \mathrm{~mm} \leq$ grade II $<1 \mathrm{~mm} ; 1 \mathrm{~mm} \geq$ grade III $\leq 2 \mathrm{~mm}$; and grade IV $>2 \mathrm{~mm}$ ) (13).

The tumor tissue and lung specimens were collected and fixed in $10 \%$ neutral formalin for $48 \mathrm{~h}$, followed by conventional paraffin embedding, slicing, hematoxylin and eosin (H\&E) staining, and observation under a light microscope.

\section{qPCR analysis}

Extraction of RNA, determination of purity and quantification of RNA. Total RNA was extracted for qPCR analysis using the TRIzol-centrifuge column method following the protocol of the manufacturer (Thermo Fisher Scientific Inc.). Considering the corresponding solvent as the control (blank), $2 \mu \mathrm{l}$ of RNA solution was tested using Merinton SMA4000. The ratios A260/A280 and A260/A230, as well as an absorption peak of continuous wavelength, were observed. The concentration of RNA solution was calculated, and the quality of the RNA extract was determined, where an A260/A280 ratio of 1.9-2.1 and an A260/230 ratio of $>2.0$ met the requirement for the subsequent reverse transcription (RT)-qPCR.

$R T$ - $q P C R$. The RT reaction mixture included $4 \mu 15 \mathrm{X}$ HiScript-II qRT SuperMix, total RNA $\leq 1,000 \mathrm{ng}$, and RNase-free $\mathrm{dH}_{2} \mathrm{O}$ up to a total volume of $20 \mu \mathrm{l}$.

The primer sequences used in the present study are listed in Table I. The PCR amplification reaction system comprised the following: 2X ChamQ SYBR Color qPCR Master Mix, $10 \mu \mathrm{l}$; forward primer, $10 \mu \mathrm{M}, 0.6 \mu \mathrm{l}$; reverse primer, $10 \mu \mathrm{M}, 0.6 \mu \mathrm{l}$; template cDNA, $8.8 \mu \mathrm{l}$; and $\mathrm{ddH}_{2} \mathrm{O}$ up to a total volume of $20 \mu \mathrm{l}$. The qPCR conditions were as follows: $95^{\circ} \mathrm{C}$ for $30 \mathrm{sec}$, $95^{\circ} \mathrm{C}$ for $10 \mathrm{sec}$ and $60^{\circ} \mathrm{C}$ for $30 \mathrm{sec}$ in a thermal cycler for 40 cycles; melting curve analysis was performed at $70-95^{\circ} \mathrm{C}$ with $0.5^{\circ} \mathrm{C}$ increments every $5 \mathrm{sec}$.

Flow cytometry. The spleen was removed and cut into $5 \times 5 \mathrm{~mm}^{2}$ pieces following removal of the adipose tissue. Spleen cell suspensions were collected and centrifuged at $300 \mathrm{x} \mathrm{g}$ for $10 \mathrm{~min}$. The cell precipitate was collected, resuspended in serum-free medium, and filtered through a 200-mesh sieve. The cell suspension was slowly dripped into an equal volume of separation medium and centrifuged horizontally at $500 \mathrm{x} \mathrm{g}$ for $20 \mathrm{~min}$. Then, the second layer of white cell suspension was collected, and the red cell layer was discarded. The cells were resuspended in five times the volume of washing liquid, centrifuged at $300 \mathrm{x} \mathrm{g}$ for $5 \mathrm{~min}$, 
Table II. Distant metastasis in the biopsy and non-biopsy groups.

\begin{tabular}{lcccccccc}
\hline & & \multicolumn{9}{c}{ No. of lung metastases } & & Lymphatic & $\begin{array}{c}\text { Cardiac } \\
\text { Groups }\end{array}$ & $\mathrm{n}$ & Total & Grade I & Grade II & Grade III & Grade IV & metastasis, n (\%) & metastasis, n (\%) \\
\hline Biopsy & 14 & $35^{\mathrm{a}}$ & 24 & 6 & 3 & 2 & $5(35.71)$ & $4(28.57)$ \\
Non-biopsy & 15 & 24 & 18 & 4 & 3 & 0 & $4(26.67)$ & $3(20.00)$ \\
Z/ $\chi^{2}$ value & - & & & -3.29 & & & 0.28 & 0.29 \\
P-value & - & & & 0.001 & & & 0.58 & 0.46 \\
\hline
\end{tabular}

${ }^{\mathrm{a}} \mathrm{P}<0.05$ vs. the non-biopsy group.
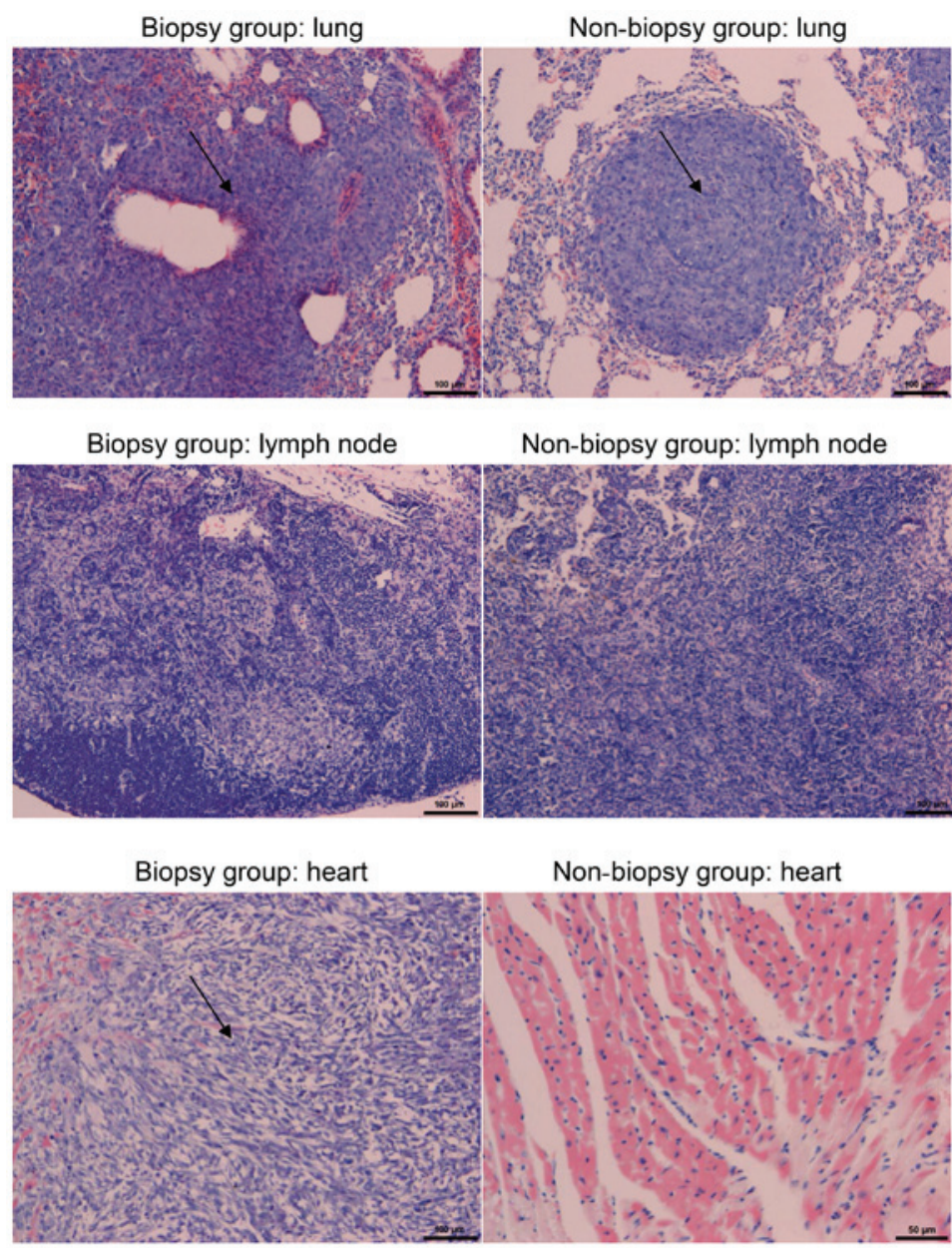

Figure 2. Lung, lymph node and heart metastases in the biopsy and non-biopsy groups (hematoxylin and eosin staining; magnification, x100).

rinsed twice, resuspended in $100 \mu 1$ staining buffer and placed on ice for incubating with antibodies. CD49b-APC and CD3-FITC antibodies (1:50) were added to the cells and incubated for $30 \mathrm{~min}$ at room temperature in the dark. In addition, CD49b-APC staining, CD3-FITC single-staining and blank groups (without antibody) were also set up. The cells of these groups were centrifuged at $300 \mathrm{x} \mathrm{g}$ for $5 \mathrm{~min}$. The cell precipitate was collected, and the cells were resuspended in $500 \mu 1$ staining buffer. CD3-FITC signals were detected using the FL-1A channel, and CD49b-APC signals were detected using the FL-4A channel. The blank group was used to determine the negative region, and the corresponding primary antibody (CD3 and CD49b) single-staining group was used to identify the positive expression area. Spleen cell suspensions were used for detection, in which the latter first used a NK Cell Isolation kit (NK2011MPK, TBD Science, Tianjin, China) to separate NK cells. The NK cells were CD49b-positive CD3-negative (UL region in the scatter plot).

Statistical analysis. Statistical analyses were performed using SPSS 22.0 software (IBM Corp., Armonk, NY, USA). Data are expressed as mean \pm standard deviation. For the univariate analysis, the classification variables were analyzed using the $\chi^{2}$ test and the Mann-Whitney $U$ test, whereas 
Table III. Relative expression of TGF- $\beta, \mathrm{SOX} 4$ and Ezh2 in the breast tumor and pulmonary metastases $\left(2^{-\Delta \Delta \mathrm{Cq}}\right)$.

\begin{tabular}{|c|c|c|c|c|c|c|c|}
\hline \multirow[b]{2}{*}{ Groups } & \multirow[b]{2}{*}{$\mathrm{N}$} & \multicolumn{2}{|c|}{ TGF- $\beta 1$} & \multicolumn{2}{|c|}{ SOX4 } & \multicolumn{2}{|c|}{ Ezh2 } \\
\hline & & $\begin{array}{l}\text { Breast } \\
\text { cancer }\end{array}$ & $\begin{array}{c}\text { Pulmonary } \\
\text { nodule }\end{array}$ & $\begin{array}{l}\text { Breast } \\
\text { cancer }\end{array}$ & $\begin{array}{c}\text { Pulmonary } \\
\text { nodule }\end{array}$ & $\begin{array}{l}\text { Breast } \\
\text { cancer }\end{array}$ & $\begin{array}{c}\text { Pulmonary } \\
\text { nodule }\end{array}$ \\
\hline Biopsy & 14 & $0.67 \pm 0.19^{b}$ & $1.55 \pm 0.54$ & $0.85 \pm 0.42^{b}$ & $6.36 \pm 4.71$ & $0.54 \pm 0.23^{\mathrm{a}}$ & $4.33 \pm 1.82$ \\
\hline Non-biopsy & 15 & $0.43 \pm 0.06$ & $0.64 \pm 0.19$ & $0.50 \pm 0.22$ & $2.49 \pm 0.91$ & $0.39 \pm 0.02$ & $1.74 \pm 0.01$ \\
\hline t-value & - & 4.70 & 2.77 & 2.80 & 1.40 & 2.41 & 2.47 \\
\hline P-value & - & 0.000 & 0.050 & 0.009 & 0.235 & 0.027 & 0.069 \\
\hline
\end{tabular}

${ }^{\mathrm{a}} \mathrm{P}<0.05,{ }^{\mathrm{b}} \mathrm{P}<0.01$ compared with the non-biopsy group. TGF- $\beta 1$, transforming growth factor- $\beta 1$; Ezh2, Enhancer of Zeste homolog 2 .

TGF- $\beta 1$

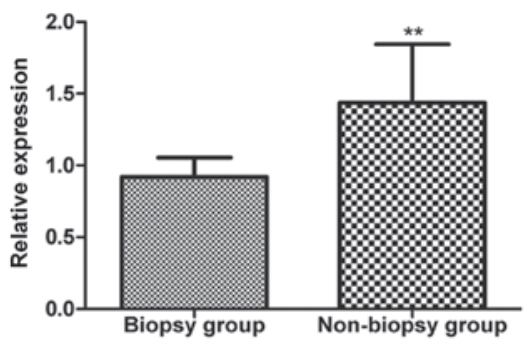

sox-4
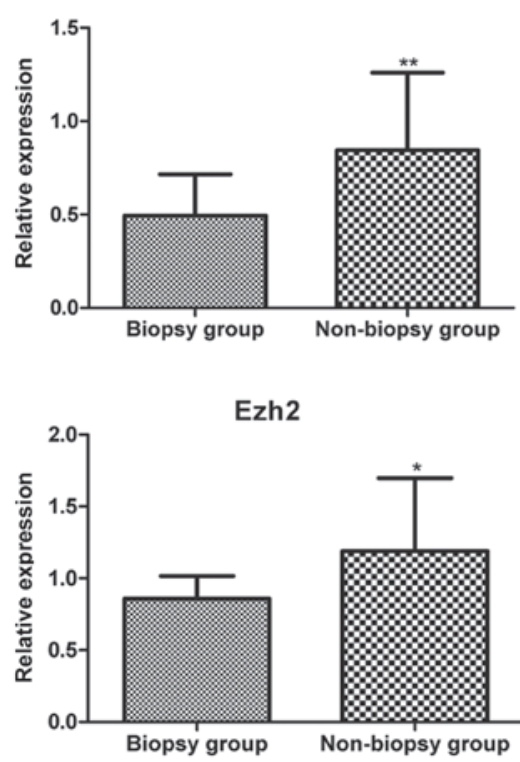

Figure 3. Relative expression of TGF- $\beta 1$, SOX4 and Ezh2 in breast tumor tissue. " $\mathrm{P}<0.05$ and ${ }^{* *} \mathrm{P}<0.01$ compared with the non-biopsy group. TGF- $\beta 1$, transforming growth factor- $\beta 1$; Ezh2, Enhancer of Zeste homolog 2.

the continuous variables were analyzed using the unpaired Student's t-test, or one-way analysis of variance with Tukey's post hoc test. $\mathrm{P}<0.05$ was considered to indicate statistically significant differences.

\section{Results}

Establishment of a model of lung metastasis associated with CNB of $4 T 1$ mouse breast cancer. The results revealed that the
Table IV. Natural killer (NK) cell content in the spleen.

\begin{tabular}{lcc}
\hline Time point & $\begin{array}{c}\text { Biopsy group } \\
(\mathrm{n}=14)\end{array}$ & $\begin{array}{c}\text { Non-biopsy } \\
\text { group }(\mathrm{n}=15)\end{array}$ \\
\hline On the day of surgery & $1.91 \pm 0.32$ & $2.75 \pm 1.82$ \\
1 week after surgery & $3.23 \pm 0.40$ & $4.58 \pm 0.83$ \\
2 weeks after surgery & $5.35 \pm 1.47$ & $7.12 \pm 2.30$ \\
\hline
\end{tabular}

model of breast cancer in situ in BALB/c mice was successfully established 14 days after the inoculation of the breast cancer cell line 4T1. At 7 days after the biopsy, the tumor volume in the biopsy group was higher compared with that in the non-biopsy group, but the difference was not statistically significant $(571.04 \pm 250.66$ vs. $478.40 \pm 320.55, \mathrm{t}=0.86$, $\mathrm{P}>0.05$; Fig. 1). The mice exhibited slow activity, decreased appetite and no significant changes in body weight following tumorectomy; although one mouse died due to lung metastasis complicated by pleural effusion in the 7 th week in the biopsy group, it had a survival rate of $93.33 \%(14 / 15)$ and all animals in the non-biopsy group survived. All measures were taken to minimize animal suffering.

Distant metastasis in the biopsy and non-biopsy groups. Starting 1 week after biopsy, three mice from each of the two groups were sacrificed every week, until all the mice had been sacrificed. The mice underwent thoracotomy, and the lungs were removed. Examination revealed that lung metastasis occurred in all mice. The metastatic foci on the lung surface were counted. The maximum tumor diameter observed in a single tumor in the study was $16.04 \times 10.98$ and $6.80 \times 6.29 \mathrm{~mm}$ from the primary and metastatic lung sites, respectively. The results are summarized in Table II. The lung metastases were observed under a light microscope following $\mathrm{H} \& \mathrm{E}$ staining. Compared with normal lung tissue, metastatic tumor cells were arranged tightly, with large, deeply stained nuclei, clear nuclear membrane, clear nucleoli and mitoses was more common. Hence, the mice were histopathologically diagnosed with an invasive cancer nest (Fig. 2). The cumulative number of nodules formed in the lung was 35 and 24 in the biopsy and non-biopsy groups, respectively, with a statistically significant difference (Mann-Whitney U test: 


\section{On the day of surgery}

A

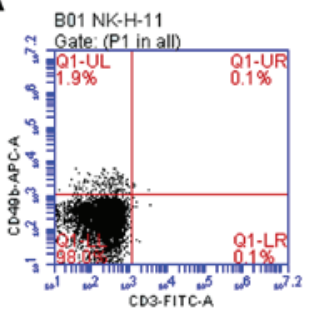

Biopsy group
B

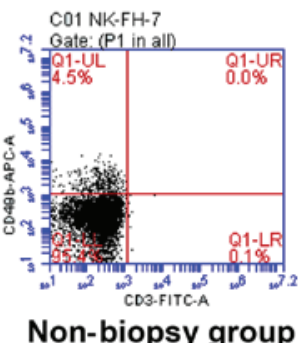

1 week after surgery

C

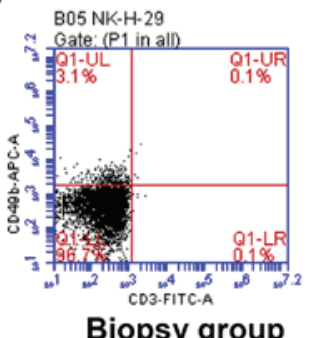

D

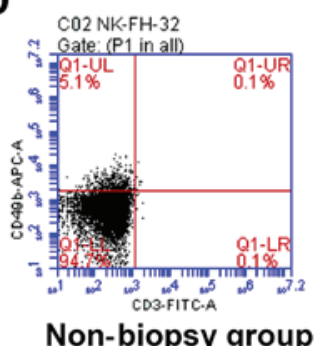

2 weeks after surgery

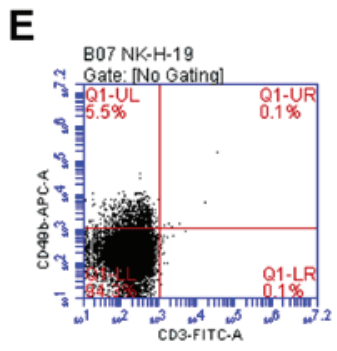

Biopsy group
$\mathbf{F}$

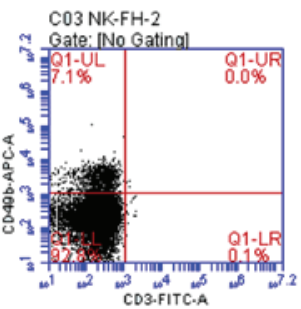

Non-biopsy group

G

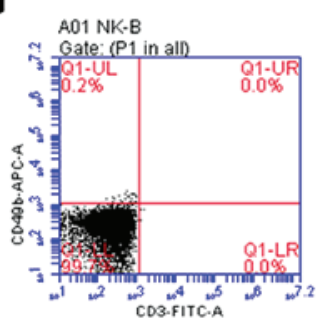

Negative control (blank)
H

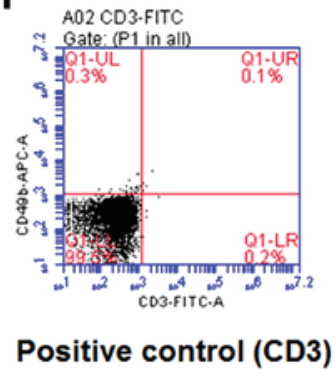

I

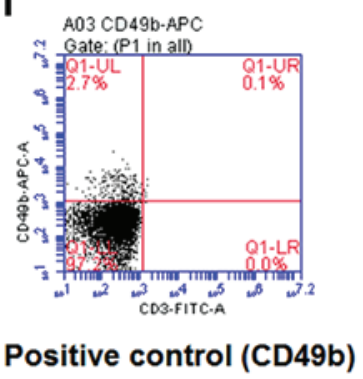

Figure 4. Changes in natural killer (NK) cell content in the spleen. Spleen cell suspensions (A and B) on the day of surgery and at (C and D) 1 week and (E and F) 2 weeks after operation were stained with CD49b-APC and CD3-FITC. (G) The blank group was used to determine the negative region, the (H) CD3 and (I) CD349b single-staining group was used to identify the positive expression area. The NK cells were CD49b ${ }^{+}$and CD3- (UL region in the scatter plot). The percentage of NK cells was calculated as follows: $\% \mathrm{CD}_{4} 9 \mathrm{~b}^{+} \mathrm{CD}^{-}$cell population $=\left(\mathrm{CD}_{4} 4 \mathrm{~b}^{+} \mathrm{CD}{ }^{-}\right.$cell number/total number of cells in the plot $) \times 100$. At the same time point, the percentage of NK cells in the biopsy group (A, C and E) was lower compared with that in the non-biopsy group (B, D and F), but the difference was not statistically significant $(\mathrm{P}>0.05)$.

$\mathrm{Z}=-3.29, \mathrm{P}<0.05$; Table II). In addition, cancer metastasis occurred in the lymph nodes and heart tissue in all mice, but the differences between the groups were not statistically significant ( $\mathrm{P}>0.05$; Table II).

Detection of the expression of TGF- $\beta 1$, SOX 4 and Ezh $2 \mathrm{mRNA}$ in the primary breast tumor and pulmonary metastasis in the biopsy and non-biopsy groups using qPCR. The expression of TGF- $\beta 1$, SOX4 and Ezh2 mRNA was found to be upregulated in the breast tumor in the biopsy group, with a statistically significant difference compared with that in the non-biopsy group $(\mathrm{P}<0.05)$. However, no significant differences were observed in the expression of TGF- $\beta 1$, SOX 4 and Ezh2 in the pulmonary metastatic nodules between the two groups (P>0.05) (Fig. 3 and Table III).

Proportion of splenic NK cells $\left(C D 49 b^{+} C D 3^{-}\right)$detected using flow cytometry. In the biopsy group, an upward trend in the percentage of NK cells was observed at 1 and 2 weeks after the operation compared with that on the day of the operation $(\mathrm{F}=37.53, \mathrm{P}<0.05)$. Similarly, in the non-biopsy group, the percentage of NK cells at 1 and 2 weeks after the operation had increased compared with that on the day of the operation $(\mathrm{F}=19.05, \mathrm{P}<0.05)$. At the same time point, the percentage of NK cells in the biopsy group was lower compared with that in the non-biopsy group, but the difference was not statistically significant $(\mathrm{P}>0.05)$ (Fig. 4 and Table IV).

\section{Discussion}

Although CNB may be used for the early diagnosis of breast cancer, the clinical effects and potential risks associated with the implementation of CNB have long been controversial. CNB is known to increase the risk of needle seeding and local tumor recurrence in patients with breast cancer. However, whether breast cancer cells enter the lymphatic system after biopsy and migrate to lymph nodes so as to effectively establish distant metastasis has not yet been confirmed $(3,4)$. Therefore, more 
evidence is required to confirm whether CNB increases the risk of local recurrence and distant metastasis (14).

In the present study, 4T1 mouse breast cancer cells were first transplanted into BALB/c mice, and $\mathrm{CNB}$ was used within 2 weeks of tumor growth to simulate clinical biopsy. In this experiment, the tumor spontaneously shifted from the mammary fat pad to the lymph nodes, lungs and heart, which is similar to the results observed in human breast cancer (15). Following successful establishment of the metastatic breast cancer model in the BALB/c mice, the effect of CNB on the following pathological mechanisms was assessed: i) Distant lung, lymph node and heart metastases; ii) changes in the immune state of cells and cytokines in the tumor microenvironment; and iii) expression of TGF- $\beta 1$, SOX4, Ezh2 and other molecules involved in EMT. Ultimately, the model was evaluated at the local and overall levels, which laid the foundation for further studies.

The results demonstrated that CNB markedly increased the incidence of distant metastases to the lungs, lymph nodes and heart in mice with breast cancer compared with that in the non-biopsy group. Previous studies have demonstrated that an increase in such metastases is associated with the changes in early immune suppression in the tumor environment. Tumors from biopsied mice exhibited a higher number of myeloid-derived suppressor cells (MDSCs) accompanied by reduced numbers of $\mathrm{CD}^{+}$and $\mathrm{CD}^{+} \mathrm{T}$ cells (16). These changes include inflammatory reaction, MDSCs recruitment, and the accompanying coagulation-enhanced NK cells toxicity. Furthermore, CNB promotes early metastasis through regulation of the genes that activate EMT (including activation of the SOX4/Ezh2 EMT pathway) $(6,7,10)$. The number of NK cells in the spleen of mice decreased after biopsy, suggesting that immunosuppression may occur. These changes are suspected to be associated with the changes in the cytosine spectrum after biopsy, which is beneficial to the pro-metastatic tumor environment (17). Recent studies have demonstrated that, compared with 4T1 cells, tumor stem cells can effectively activate platelets, induce platelets to secrete more TGF- $\beta 1$, reduce NKG2D expression, and inhibit the antitumor activity of NK cells (18); however, the specific mechanisms remain to be elucidated. One possible explanation is that the metastasis of breast tumor cells to the lung is also likely to have occurred as a result of needle puncture that may have occurred during the biopsy, as no lymphatic or cardiac metastases were observed. In addition, the increase in TGF- $\beta 1$, SOX4 and Ezh2 mRNA may have been induced by inflammatory changes caused by the needle biopsy, which were not observed in the pulmonary metastasis nodule tissues.

Furthermore, the qPCR results demonstrated that the expression of mRNA of TGF- $\beta 1$ and its related factors SOX4 and Ezh2, which are currently considered as the main EMT regulatory factors (19), increased significantly after biopsy. These findings suggested that the activation of the TGF- $\beta 1 /$ SOX4 EMT pathway may contribute to the migration and exudation of circulating tumor cells (CTCs), thereby increasing the risk of metastasis (20). In addition to activating the TGF- $\beta 1$ signaling pathway, SOX4 can also transform cancer epithelial cells into cancer stem cells. Thus, SOX4 increases the proportion of $\mathrm{CD} 44^{+} \mathrm{CD} 24^{-/ \text {low }}$ breast cancer stem cells, indicating that SOX4 can induce breast epithelial cells to assume the characteristics of stem cells (21). Previous studies demonstrated that the expression of SOX4 is associated with high rates of metastasis in early lymph node-negative patients, while another study associated SOX4 expression with patients with triple-negative breast cancer, which makes it a marker of poor prognosis (6,7). SOX4 can bind with EZH to promote the expression of Ezh2 and increase H3K27me3 to induce EMT (7). Ezh2, the human homologue of the Drosophila Melanogaster enhancer of zeste gene, possesses a histone methyltransferase activity, which can directly induce EMT and promote tumor metastasis by inhibiting E-catenin expression (22). Combined with these studies, the findings of the present study confirmed the key role of EMT and related molecules in the CNB-induced metastasis of breast cancer. EMT allows the transformation of tumor cells into an invasive mesenchymal phenotype and their entry into the circulatory system and metastasis to distant organs. Furthermore, a reciprocal regulation between SOX4 and miR-129-5p via the SOX4/EZH2 complex mediated H3K27me3 modification was recently identified, and indicates that miR-129-5p is an important miRNA modulating EMT in breast cancer cells (23). The expression of the EMT regulators SOX4 and Ezh2 is upregulated in breast cancer tissue (16), and it may become a potential biomarker for predicting the metastasis of breast cancer (24).

In conclusion, the experimental results demonstrated that $\mathrm{CNB}$ was associated with a significant increase in the incidence of lung metastases in breast cancer mouse models, which may be associated with the fact that CNB exerts an immunosuppressive effect, creates a pro-metastatic tumor microenvironment, and promotes TGF- $\beta /$ SOX4-induced EMT.

\section{Acknowledgements}

Not applicable.

\section{Funding}

This study was supported by the Experimental Animals Science and Technology Project of Zhejiang Province, China (grant no. 2016C37095), and the Science and Technology Project of Jinhua, China (grant no. 2018-3-024).

\section{Availability of data and materials}

The datasets supporting the results of this study are included in the published article.

\section{Authors' contributions}

YF, FG and MD conceived and coordinated the study, designed, performed and analyzed the experiments, and wrote the manuscript. YL and XF performed the data collection and analysis. $\mathrm{HC}$ and $\mathrm{HZ}$ performed and analyzed the experiments. All authors reviewed the results and approved the final version of the manuscript.

\section{Ethics approval and consent to participate}

This study was approved by the Animal Ethics Committee of the Jinhua Center of Laboratory Animals. All experimental procedures were carried out in accordance with the animal testing regulations. 


\section{Patient consent for publication}

Not applicable.

\section{Competing interests}

The authors declare that they have no conflict of interest.

\section{References}

1. Torre LA, Bray F, Siegel RL, Ferlay J, Lortet-Tieulent J and Jemal A: Global cancer statistics, 2012. CA Cancer J Clin 65: 87-108, 2015

2. Li Y, Arellano AR, Bare LA, Bender RA, Strom CM, Devlin JJ: A multigene test could cost-effectively help extend life expectancy for women at risk of hereditary breast cancer. Value Health 20 : $547-555,2017$.

3. Ljung R, Sennerstam R, Mattsson F, Auer G and Lagergren J: Anticoagulant medication at time of needle biopsy for breast cancer in relation to risk of lymph node metastasis. Int J Cancer 135: 238-241, 2014.

4. Cho E, Kim MH, Cha SH, Cho SH, Oh SJ and Lee JD: Breast cancer cutaneous metastasis at core needle biopsy site. Ann Dermatol 22: 238-240, 2010

5. Park CY, Min KN, Son JY, Park SY, Nam JS, Kim DK and Sheen YY: An novel inhibitor of TGF- $\beta$ type I receptor, IN-1130, blocks breast cancer lung metastasis through inhibition of epithelial-mesenchymal transition. Cancer Lett 351: 72-80, 2014

6. Parvani JG and Schiemann WP: Sox4, EMT programs, and the metastatic progression of breast cancers: Mastering the masters of EMT. Breast Cancer Res 15: R72, 2013.

7. Tiwari N, Tiwari VK, Waldmeier L, Balwierz PJ, Arnold P, Pachkov M, Meyer-Schaller N, Schübeler D, van Nimwegen E and ChristoforiG: Sox4 is a masterregulator of epithelial-mesenchymal transition by controlling Ezh2 expression and epigenetic reprogramming. Cancer Cell 23: 768-783, 2013.

8. Borin TF, Shankar A, Angara K, Rashid MH, Jain M, Iskander A, Ara R, Lebedyeva I, Korkaya H, Achyut BR and Arbab AS: HET0016 decreases lung metastasis from breast cancer in immune-competent mouse model. PLoS One 12: e0178830, 2017.

9. Wang W, Belosay A, Yang X, Hartman JA, Song H, Iwaniec UT, Turner RT, Churchwell MI, Doerge DR and Helferich WG: Effects of letrozole on breast cancer micro-metastatic tumor growth in bone and lung in mice inoculated with murine 4T1 cells. Clin Exp Metast 33: 475-485, 2016.

10. Ministry of Health of the PRC: GB 5749-2006 sanitary standard for drinking water. China Standard press, Beijing, 2006 (In Chinese).

11. General Administration of Quality Supervision,Inspection and Quarantine of the People's Republic of China: GB 14924. 3-2010 Nutritional components of feeds for experimental animals. China Quality Inspection press, Beijing, 2011 (In Chinese).

12. Juratli MA, Siegel ER, Nedosekin DA, Sarimollaoglu M, Jamshidi-Parsian A, Cai C, Menyaev YA, Suen JY, Galanzha EI and Zharov VP: In vivo long-term monitoring of circulating tumor cells fluctuation during medical interventions. PLoS One 10: e0137613, 2015.
13. Wan H, Wu X, Dong J, Yu X, Feng J, Li X and Lu D: The action mechanism underlying the anti-tumor effects of 'Ruaishuhou herbs' against highly metastatic breast cancer. Tumor 27: 691-693, 709, 2007 ( In Chinese).

14. Liebens F, Carly B, Cusumano P, Van Beveren M, Beier B, Fastrez $M$ and Rozenberg S: Breast cancer seeding associated with core needle biopsies: A systematic review. Maturitas 62: 113-123, 2009.

15. Zhang Y,Zhang N, Hoffman RM and Zhao M: Surgically-induced multi-organ metastasis in an orthotopic syngeneic imageable model of 4t1 murine breast cancer. Anticancer Res 35: 4641-4646, 2015.

16. Mathenge EG, Dean CA, Clements D, Vaghar-Kashani A, Photopoulos S, Coyle KM, Giacomantonio M, Malueth B, Nunokawa A, Jordan J, et al: Core needle biopsy of breast cancer tumors increases distant metastases in a mouse model. Neoplasia 16: 950-960, 2014

17. Bembenek A, Li J, Loddenkemper C, Kemmner W, Stein H, Wernecke KD and Schlag PM: Presence of mature DC-Lamp+ dendritic cells in sentinel and non-sentinel lymph nodes of breast cancer patients. Eur J Surg Oncol 34: 514-518, 2008.

18. Wang S, Zhang Y, Cong W, Liu J, Zhang Y, Fan H, Xu Y and Lin H: Breast cancer stem-like cells can promote metastasis by activating platelets and down-regulating antitumor activity of natural killer cells. J Tradit Chin Med 36: 530-537, 2016.

19. Hasegawa S, Nagano H, Konno M, Eguchi H, Tomokuni A, Tomimaru Y, Asaoka T, Wada H, Hama N, Kawamoto K, et al: A crucial epithelial to mesenchymal transition regulator, Sox4/Ezh2 axis is closely related to the clinical outcome in pancreatic cancer patients. Int J Oncol 48: 145-152, 2016.

20. Zhang J, Liang Q, Lei Y, Yao M, Li L, Gao X, Feng J, Zhang Y, Gao H, Liu DX, et al: SOX4 induces epithelial-mesenchymal transition and contributes to breast cancer progression. Cancer Res 72: 4597-4608, 2012.

21. Chen L, Xiao Z, Meng Y, Zhao Y, Han J, Su G, Chen B and Dai J: The enhancement of cancer stem cell properties of MCF-7 cells in 3D collagen scaffolds for modeling of cancer and anti-cancer drugs. Biomaterials 33: 1437-1444, 2012.

22. Luo H, Jiang Y, Ma S, Chang H, Yi C, Cao H, Gao Y, Guo H, Hou J, Yan J, et al: EZH2 promotes invasion and metastasis of laryngeal squamous cells carcinoma via epithelial-mesenchymal transition through H3K27me3. Biochem Biophys Res Commun 479: 253-259, 2016.

23. Luan QX, Zhang BG, Li XJ and Guo MY: miR-129-5p is downregulated in breast cancer cells partly due to promoter $\mathrm{H} 3 \mathrm{~K} 27 \mathrm{~m} 3$ modification and regulates epithelial-mesenchymal transition and multi-drug resistance. Eur Rev Med Pharmacol Sci 20: 4257-4265, 2016.

24. Jang SH, Lee JE, Oh MH, Lee JH, Cho HD, Kim KJ, Kim SY, Han SW, Kim HJ, Bae SB and Lee HJ: High EZH2 protein expression is associated with poor overall survival in patients with luminal a breast cancer. J Breast Cancer 19: 53-60, 2016. 